the posterior wall of the pharynx after the attachments of the tongue to the jaw had been freely divided, the man's hreathing was perfectly easy-much more so than when the ?head was raised or lay level with the trunk. Before the patient left the theatre I demonstrated this fact several times to the students present, and thoroughly convinced them and myself of its correctness.

The experience of this case led me to place the head in the same position in my next operation on the throai (thyrotomy); and since then I have performed many operations in this way on the mouth and throat with complete success, and with great facility as regards the prevention of blood passing into the air-passages, the obtaining a good view of the parts, and the carrying out of the necessary manipulations.

Among the operations in which I have used this method have been, a second case of thyrotomy, two cases of tumour of the palate, one case of large epulis, and three cases of cleft palate. In all these operations I have been impressed with the advantages of this position of the head. Complete anæsthesia by means of chloroform, or a mixture of chloroform and ether, has been kept up without any inconvenience during the whole proceedings.

My present method of keeping the head in this position is to have it hanging over the end of the table and supported there by the hands of an assistant ; but I am having a little addition made to my operating table which will allow the head to be supported in this position more efficiently.

Edinburgh,

\section{A NOTE ON}

\section{VASO-MOTOR AND TROPHIC NEUROSES}

\section{By THOS. STRETCH DOWSE, M.D., F.R.C.P. ED.,}

PHYSICIAN TO THE HOSPITAL FOR PARALYSIS AND EPILEPSY, REGENT'SPARK; FORMERLY PHYSICIAN SUPERINTENDENT OF THE CENTRAL LONDON SICK ASYLUM.

\section{(Concluded from page 648.)}

I Do not profess to consider fully in the present communication the nutritive lesions which are due to injuries of nerves, but I will just take a brief glance at such conditions, in order to express my present ideas the more clearly and with some completeness. Schroeder van der Kolk, Brown-Séquard, and our countryman J. Rèid, have shown that in the severance of the sciatic nerve the muscles, bones, and skin become atrophied, and that this was not so much in consequence of their being dissociated from the mervous centres as in consequence of the functional inaction of the paralysed member. The best practical example with which I am acquainted for showing how lesions of nutrition, caused by central disease of the brain and spinal cord, follow a direct histological law, is that of bedsores, which spread with such alarming rapidity over the lower part of the spine and buttocks. For instance, in a case of apoplexy in which the hæmorrhage exists only in one hemisphere of the brain, with paralysis of the opposite limbs, we invariably find that the destruction of tissue commences in and is limited to the buttock of the paralysed side. On the contrary, when a bedsore is of acute spinal origin, it occupies the median line over the sacrum, and extends symmetrically on either side towards the surrounding textures. The same rule holds good in lesions of nutrition of the lower limbs from spinal softening; if the softening be bilateral the lesions will be bilateral, or if the softening be unilateral the lesions will usually be unilateral. These are facts well known to the experienced physician and surgeon. I bring them thus forward because I am strongly inclined to believe that they form the best data on which to rely as proof that the vascular derangements and troubles of nutrition, such as skin diseases, bedsores, wasting of muscles, \&c., which are made evident to us during life, follow precisely the same law in producing degenerative changes and functional disorders throughout the whole course of the cerebro-spinal sympathetic system, and are, in fact, the cause or causes of most of the so-called nervous affections which we have under our consideration.

In the first place, I will note some of the classical ex. amples of diseases well known to us, and which are more or less essentially due to defective nervous influence in the regulation of nutrition, secretion, and circulation. Of these, Graves' disease, angina pectoris, hemicrania, and atrophy and hypertrophy of the muscles, skin and its appendages, are, perhaps, the most noteworthy. In Graves' disease we have a condition which certainly of late years has been looked upon in the light of a neurosis, by Handfield Jones, Fletcher, Laycock, von Graefe, Trousseau, and others, of this disease the three cardinal symptoms and signs are, protrusion of the eyeballs, palpitation of the heart, and an enlargement of the thyroid gland. It is not necessary that these characteristics should occur simultaneously, but they are usually associated, in a more or less marked degree, during the course of the disease. That this disease is due to an especial idiosyncrasy of the nervous system cannot, as far as my observation goes, be doubted for one single moment. Undoubtedly there are exciting causes, yet the influence which they exercise can be referred without much difficulty to their action upon the vaso-motor, sympathetic, and trophic nerves. We have seen what takes place when the cervical sympathetic is both irritated and divided; now the analogy between these alterations of function and what we meet with in Graves' disease is deserving of consideration. The dilatation of the vessels is indicated by the strongly pulsating, prominent, and frequently tortuous little arteries, which are in this region supplied by the carotid arteries, and again more especially by the swollen arteries of the thyroid gland. The coming on of goitre so quickly, in the course of a few days, the softness of the swelling, the perceptible pulsation of the thyroid arteries, the lond blowing sound which is heard over them, the rapid increase and decrease of the tumour, according to the force of the contractions of the beart, and the engorged condition of the veins so frequently seen on the surface of the gland, all these clearly point to the conclusion that we have to do chiefly with a dilatation of the vessels which are distributed in the thyroid body, and this conclusion is fully borne out by anatomical investigation. ${ }^{1}$ To say nothing of the ex. treme discomfort to the patient, caused by the palpitation and rapid action of the heart, there is one especial feature of this disease which is of the highest practical value, and which is deserving of careful consideration-I mean the pro. trusion of the eyeballs. This protrusion is not often con fined to one eye alone, but usually extends to both eyes. ${ }^{2}$

Eulenburg and Guttmann ${ }^{3}$ have shown that, after division of the cervical sympathetic, no exophthalmos occurs, but rather a sinking of the eyeball within the orbit. If, however, the central end of the divided nerve be subjected to electrical stimulation, the eyeball is protruded, and we have exophthalmos. Again, it has been shown that exophthalmos follows irritation merely of the cervical sympathetic system yet I would not have it to be inferred that this protrusion of the eyeball is due entirely to interchange, as between it and the cervical ganglia of the sympathetic, since any serious check to the circulation of blood in the head will produce similar effects.

In angina pectoris we find a grouping together of symptoms which show pretty clearly that it is a neurosis, although the coronary arteries have undergone atheromatous and other changes. For instance, we have the paroxysmal character of the pain in the region of the heart, and usually extending over the left side of the chest and down the left arm, and sometimes down both sides and arms, with an associated sensation of anxiety and constriction and of other vaso. motor and sensitive disturbances. Laennec called it "neuralgia cordis," Tronsseau "an epileptic form of neuralgia," and Stokes "an hyperæsthetic state of a weakened heart." Barkow even called it "a trophoneurosis of the heart," and, indeed, various other names have been given to it by different observers. The true condition of it, how. ever, as far as we know, has been determined by the modern researches of physiologists, and notably by those of Lauder Brunton. ${ }^{4}$ Eulenburg and Guttmann have given to this subject considerable attention. ${ }^{5}$ They say truly that in discussing angina pectoris they are unable to argue from the state of any one system of cardiac nerves, and that they can

1 Eulenburg and Guttmann: Sympathetic System of Nerves, 1879. Naumann : Deutsche Klinik, 1853. F. Banks: Dublin Hosp. Gaz., 1855. Fournier et Ollivier : Únion Méd., 1868, p. 95.

2 Chisholm : Med. Times and Gaz., 1871.

3 Op. cit. 1879.

4 THE LANCET, 1867, and other communications.

5 Eulenberg: Angina. Ziemssen's Cyclopædia of the Practice of Medicine, vol, xiv. Eulenberg and Guttmann : Sympathetic System of Nerves, 1879 . 
only analyse the symptoms physiologically, and endeavour to show, on experimental grounds, in what way the different systems of nerves may be concerned in producing this disease. I will not here attempt to enter into their arguments.

$A$ teaching and instructive lesson is offered to us in the action of the remedial agents which are employed in the treatment of this singular affection. I allude more particularly to those two drugs, the nitrite of amyl and the secale cornutum, both which exercise such a specific and definite action upon the circulatory system of nerves. I have used these remedies with really charming results. The chief action of the first-mentioned, as far as I could make out, consists in paralysing the vaso-motor nerves and in equalising the general blood-pressure.

In progressive hemiatrophy of the facial muscles, as well as in muscular atrophy, and in muscular pseudo-hypertrophy, we have conditions which are more or less intimately associated with vaso-motor and trophic derangements. Vague theories have, from time to time, been brought forward in regard to these diseases. Nothing, however, is decidedly known with regard to facial wasting; yet it would appear, from the observations of such careful neurologists as Romberg, Berson, and Samuel, that it is considered as being connected with the nerves of nutrition. Stilling believed it to be the result of disturbed function in the vasomotor nerves, especially in those filaments which are included in the trigeminus, and which are destined for the vessels of the head. Brunner has lately recorded one striking instance of unilateral atrophy of the face, and which, he believes, points to a diseased state or a condition of permanent irritation of the cervical sympathetic. Brunner thinks that the symptoms recorded in his case correspond to the state which is experimentally produced in animals by galvanisation of the divided cervical sympathetic or of its ganglion supremum.

It is as yet a question as to the part played by the sympathetic and vaso-motor nerves in the production of atrophy and hypertrophy of muscles. However, it has been fairly substantiated that in progressive muscular atrophy there is more or less deseneration of the anterior roots of the spinal nerves and of the large motor and other cells of the grey matter of the anterior cornua of the spinal cord; but whether this change be primary or secondary to other changes in the peripheral vaso-motor nerves is not as yet decided. The generally accepted doctrine, however, is that which has been promulgated by Charcot, Lockhart Clarke, and many other recent observers-namely, that it originates in the cornua of the grey matter of the anterior columns.

Schneevogt first drew attention to the accompanying affection of the sympathetic in this disease. In the case investigated by him, the brain and spinal cord were normal as far down as the fourth cervical nerve, and considerably softened and extensively infiltrated with finely granular fat and granulation cells. From the fifth cervical to the second dorsal nerve, the posterior roots of the cervical nerves were unchanged, but the anterior were strikingly thinned, and especially the five upper, which consisted only of some very slender filaments. The cervical cord of the sympathetic was almost converted into a cord of adipose tissue, in which the nerve-fibres were replaced by flat cells containing crystals. The cervical ganglia had almost completely degenerated into fatty tissue, while the thoracic part of the sympathetic likewise contained some fatty matter. From the stages of the different processes which Jaccoud examined in two of his patients, he regards it as unquestionable that the disease began in the cervical sympathetic, and spread thence both centripetally and centrifugally to the surrounding nervous structures. ${ }^{6}$

If the evidence in respect to the origin of the disease of muscular atrophy be so conflicting, it is much more so in respect to pseudo-hypertrophic paralysis. By some this paralysis has been considered as a primary affection of the muscles, and by others as a neuropathic disease. Griesinger ${ }^{7}$ considers it to be a disease essentially of the vaso-motor nerves; and Benedikt" mentions it among the "trophoneuroses," and believes one of his cases to have been a paralysis of the sympathetic. In a case investigated by $\mathrm{M}$. Charcot the state of the spinal cord and peripheral nerves was entirely a negative one. In a case recorded by Eulenburg, ${ }^{9}$

6 Jaccoud: Bulletin de la Soc. Méd. des Hôpitaux de Paris; Union IÉd., 1865 , tom Xxp., No. 4 , p. 60

Archiv der Heilkunde, 1864 (6ter Jahrgang), p. 171.

Elektrotherapie, Vien, 1869 , p. 86 , ff

9 Eulenberg, Berl. Klin. Wochenschrift, 1865. in which Cohnheim made the examination, the result with respect to the nervous system was perfectly negative, and microscopic examination revealed no pathological changes either in the brain, the spinal cord, medulla, peripheral nerves, or sympathetic system.

A very great deal has yet to be learned in reference to this subject; yet, as clinical observers, we can but feel greatly indebted to the physiologist, who has of late years done so much to make the bedside study of disease scientific and pleasurable, rather than a mere question of pain, tongue pulse, and bowels.

old Burlington-street, w.

\section{CASE OF \\ STONE IN THE BLADDER; LITHOTRITY AND REMOVAL OF FRAGMENTS BY MEANS OF BIGELOW'S APPARATUS AT ONE SITTING.}

\section{BY WALTER J. COULSON, F.R.C.S.}

Francrs M-, aged twenty-eight, bootmaker, came under my care on Sept. 25th, 1879. He had suffered for the last eighteen months from frequency of micturition, great pain along urethra and at extremity of glans penis, especially after micturition, occasional retention of urine, and occasional slight hæmaturia. The calls to pass urine at the time of my seeing him were very frequent, about every quarter of an hour during the day. Much straining accompanied the act. During the night, however, he was more comfortable, and was disturbed but once or twice. He was a thin, pale man; for some time past his symptoms had prevented him from following his employment, and he had not been able to obtain sufficient food. Urine light yellow, acid reaction, sp. gr. 1018, deposited a cloud of mucus ; no albumen and no casts of tubes. Evening temperature $99^{\circ}$

A calculus was detected on sounding, and the patient was ordered to remain in bed for a few days.

On Oct. 1st, chloroform having been administered, I introduced a flat-bladed lithotrite and crushed the stone several times. The instrument was then withdrawn, with some detritus between its blades. Another lithotrite was introduced, and the fragments repeatedly caught and crushed, in all eleven times. Bigelow's apparatus was then used, and fragments and débris, weighing thirty-five grains, were drawn into the receiver. A lithotrite was again introduced and the bladder explored, but no fragments of calculus could be detected. The operation lasted twenty-four minutes. There was no trace of hæmorrhage. The calculus was found to be composed of uric acid. The operation was not followed by any symptoms of rigor. The urine passed an hour afterwards was very slightly tinged with blood, and contained a very small quantity of fine detritus, fine enough to pass through the muslin used as a filter.

2nd.-Has slept well, but complains of slight headache. Tongue clean, appetite bad. Temperature : Morning $102^{\circ}$; evening $104^{\circ}$. Urine contains a little fine dust and some amount of mucus.

3rd.-Complains of wandering pain about the body generally. Appetite still bad. Can retain his urine for an hour at a time; there is still a slight sediment of fine dust. Evening temperature $105^{\circ}$. A saline aperient ordered.

4th.-Feels better. Has no pain in passing urine, which is now free from deposit. Temperature $100^{\circ}$

On the 8th the patient expressed himself as feeling very well. He had been allowed to leave his bed since the 4 th. He could retain his urine for three or four hours at a time without discomfort; there was only a little smarting along the urethra on micturition. Temperature normal. Examined the bladder with a lithotrite; no fragments of stone could be found. Ordered a mixture with bicarbonate of potash.

On the 9th his cure was complete.

The ease with which the stone was dealt with, and the fact that by far the greater portion of it was removed from the bladder at a single sitting, suffice to demonstrate the advantages of Dr. Bigelow's method when applied to suitable cases. After the withdrawal of the evacuating catheter, all 